\title{
Building a Center for Writing and Communication: Inclusion, Diversity and Writing in the Indian Context
}

\author{
Kanika Singh
}

\section{Ashoka University and Its Centre for Writing AND COMMUNICATION}

Ashoka University is a private university established in 2014 in the north Indian state of Haryana on the outskirts of Delhi. Ashoka's study programs draw upon a liberal arts model of education where students are introduced to a variety of disciplines and ways of knowing the world. The undergraduate program offers students the flexibility to choose a combination of courses. For instance, one may major in History and do a minor in Visual Studies, or Media Studies, or opt for interdisciplinary majors like Economics and History. Moreover, the students are not expected to be passive receivers of knowledge. Ashoka's pedagogy emphasizes on making the university a space for critical thinking and the teacher-student interaction involves pedagogical tools that focus on student participation in

K. Singh $(\bowtie)$

Ashoka University, Haryana, India

e-mail: kanika.singh@ashoka.edu.in

(C) The Author(s) 2020

C. S. Sanger and N. W. Gleason (eds.),

Diversity and Inclusion in Global Higher Education, https://doi.org/10.1007/978-981-15-1628-3_8 
unpacking knowledge and creating it anew. Rather than producing rotememorized content, the students are encouraged to be critical thinkers where they learn to appreciate, examine, discuss, critique and innovate on what they learn about the world.

Theoretically, this approach is not a recent one, ${ }^{1}$ nevertheless, it is surprising how little it is practiced in schools and in institutions of higher education in India. Perhaps only a handful of schools, colleges and universities can boast of an active engagement with pedagogy where the students have the opportunity to be participants in the teaching-learning process. In most institutions, the case is overwhelmingly of the student being a passive receiver of knowledge with little idea of how the material present in the school textbook is relevant to the world. ${ }^{2}$ Even those of us who had the benefit of a good quality education have not encountered this in our school experience. A friend and fellow-academic whose research focuses on multilingual education remembers her own classes of science and mathematics at school. She was a good student, interested in these subjects and she recalls having enjoyed solving mathematical equations or problems based on conductors and resistances in a circuit diagram. However, she observes, 'While I enjoyed solving these problems on paper, I can't recognize the same concept when it appears in the real world. I got a great kick when I solved mathematical puzzles, but how do matrices shape the world we live it? How do they help me understand the real world?'3

Ashoka's pedagogical vision thus makes a departure from many existing institutions of higher education in India. Moreover, this approach is supported by good infrastructure and resources available to the students and the teachers, a good teacher-student ratio and close mentorship and learning support available to students. The Centre for Writing and Communication (CWC) at Ashoka is instrumental in providing close mentorship and learning support to students.

${ }^{1}$ Paulo Freire, Pedagogy of the Oppressed, translated by Myra Bergman Ramos (Great Britain: Penguin, 1972); bell hooks, Teaching to Transgress: Education as the Practise of Freedom (New York: Routledge, 1994).

2 This is because of a variety of factors including lack of resources, poor teacher-student ratio, ill-equipped and overworked teachers and several institutional and social factors.

${ }^{3}$ Shivani Nag, conversation with author, May 16, 2019. 
The CWC was established in 2014 as the university welcomed its first undergraduate class. It was envisaged as an integral part of Ashoka's curriculum and pedagogy. Initially, CWC's responsibility was to provide writing support to the Introduction to Critical Thinking (ICT) courses. The ICT is a writing course (taught in English) taken by all undergraduates at Ashoka in the very first semester of their undergraduate program, where close reading and critical analysis of content and learning to respond to it is introduced to students through writing exercises. The classroom teaching of the ICT was supported by one-on-one sessions conducted by the CWC where the students can brainstorm ideas, discuss their drafts and improve their writing samples. CWC played an important role in the pedagogical practices of developing critical thinking skills in students, principally through writing pedagogy.

In the last couple of years, Ashoka has seen rapid expansion in the number of students and the number and the levels of courses. While traditional programs like Economics, Mathematics, History, English and Political Science have expanded, several new programs have been introduced including Media Studies, Visual Studies, Environment Studies, Biology and Physics. The undergraduate cohort makes up the bulk of the student strength, and now postgraduate and graduate students are also part of the university. As a private university near Delhi with very high fees and the lack of caste-based reservation policy, ${ }^{4}$ Ashoka's student body overwhelmingly constitutes students from an elite, English-speaking background. Ashoka through its financial aid program has admitted a number of students from economically weaker sections, and from non-metropolitan areas within India. So, it is not only the numbers that have increased but also there is a student body with differing learning needs as a result of growing interdisciplinarity, different levels of courses, varying levels of fluency in English among students, and varied educational and social background of the students.

As the university has grown, the CWC too has had an opportunity to reconsider the role it can play in the university. As the head of the CWC, my responsibilities include both formulating an intellectual vision for the CWC and devising a working model to achieve it. For the purposes of this volume, I focus on the intellectual task before the CWC.

\footnotetext{
${ }^{4}$ As is mandatory in a government or public university.
} 
This paper shares some of the questions we have grappled with, the possibilities we have considered, and the initiatives taken since the year 2017 as an attempt to creatively engage with the issues of critical thinking, knowledge creation, pedagogy and inclusion within Ashoka and in India. Our work has been grounded in the following eight fundamental issues of inclusive writing support.

1. The interdisciplinary nature of the curriculum meant that the CWC should be willing and equipped to engage with a wide variety of disciplinary perspectives and study material, and not only text-based material, but also oral, visual, ethnographic, numerical, experimentbased and performative.

2. In the Indian context, displaying fluency in English is a marker of modernity and class. ${ }^{5}$ At Ashoka, English is the sole language of instruction, and indeed, of both formal and informal communication. In such a situation, how can pedagogy be made inclusive? On the one hand, equipping students with English language skills is helpful in enabling them to engage with the world. On the other hand, doing so without considering the languages they are comfortable in is an active form of exclusion.

3. While recognizing that providing English language support was necessary in Ashoka, how could we overcome the limitations of English language teaching in India?

4. Further, it is even more crucial to develop an English language support program that helps students not only learn the language but equips them be able to transfer knowledge from their contexts into academic writing in English.

5 . While writing is the primary medium of knowledge production and teaching-learning practices in the university spaces, given the diversity of the Indian context (as a multilingual society, with thriving oral, performative, visual and textual traditions), it was important to consider if writing was the only way of 'critical thinking.' And should

${ }^{5}$ Vaidehi Ramanathan, The English-Vernacular Divide: Postcolonial Language Politics and Practice (New Delhi: Orient Longman, 2005); Shalini Advani, Schooling the National Imagination: Education, English, and the Indian Modern (New Delhi: Oxford University Press, 2009). 
reading, writing, speaking in English be the only way to 'do' critical thinking? What are the ways in which Indian languages can be included in higher education pedagogy, without excluding English?

6. As tutors and instructors, an important factor to consider was the use of technology by the students for accessing and processing information. Traditional methods of reading, writing, accessing information-books, magazines, newspapers, all in printed form and even writing by hand-are rapidly become outdated. At least in Ashoka, for the majority of students, the primary method of accessing information and communicating is through digital platforms. My students take notes on their mobile devices and laptop screens, if at all, and they are extremely reluctant to visit the library to hunt for reading material; they would much rather scourge the internet for a digital copy of the readings. So they are not only reading different things, they are reading differently. There are a number of studies that show us that accessing content only digitally is a severely limiting way of knowing the world, and it also changes the way we understand the world. ${ }^{6}$ In this scenario, how do we read, write and communicate critically? How can we ensure that the teacher-learner interaction is effective? And what are its implications for inclusive education?

7. With the growing numbers, the CWC had to reconsider the one-onone sessions as the primary mode of engagement with the students. It was important to find alternative ways of interacting with the students and the teachers, within and outside the classroom and the curriculum.

8. And finally, how could the CWC contribute to make pedagogy at Ashoka inclusive?

\section{Building a Center for Writing ANd Communication}

The first step was recognizing that the Centre with its mandate of 'writing' and 'communication' is in the unique position of engaging with all the stakeholders in the university. This is because every activity in the

\footnotetext{
${ }^{6}$ For instance, Maryanne Wolf argues that humans' dependence on digital technology alters the functioning of the brain, affecting our capacity to think critically and reflect and even to empathize. See Wolf, Reader, Come Home: The Reading Brain in a Digital World (New York: HarperCollins, 2018).
} 
human world, particularly knowledge production and higher education, is some form of 'writing' or 'communication,' and therefore, can be critically seen through the lens of 'writing' and 'communication.' Such an approach helped us recognize the CWC as a dynamic space where the skills as well as the politics of writing and communication, the questions of pedagogy, language, curriculum and inclusion could be debated and experimented with. It is with this vision that the CWC has worked since the year 2017.

The most crucial aspect of creating such a Center is the composition of its team. We made a conscious effort to create a team where its members came from diverse backgrounds-disciplinary, linguistic and with the experience of writing in different contexts (academic, journalistic, popular, fiction and non-fiction). We particularly value educators with experience in creating learning materials for different kinds of audiences. Some of our team members have experience working with school children and neo-literates, creating learning material in distance mode, and as language teachers for English and other Indian languages. And, they have varying levels of educational qualifications: some have a Ph.D., others have a postgraduate degree. The CWC team includes anthropologists working on humor, music and food, a lawyer researching on manual scavengers, students of English literature and composition, a scholar and writer of children's books, artists, journalists, translators, and a historian researching with textual, visual, ethnographic material. These scholars and professionals have worked with different kinds of writing and communication practices which when put together in a university setting, introduces a range of ways of thinking about the world-a factor, that is in keeping with Ashoka's model of a liberal arts education. The diversity of expertise in the team, I believe, is instrumental to the CWC's vision. It is only when a group of scholars and professionals with their diverse experience, work closely with each other through the year to discuss reading, writing, communication and pedagogy, can we truly begin thinking about critical thinking and inclusivity.

\section{CWC ANd Introduction to Critical Thinking}

CWC's close association with the Introduction to Critical Thinking course (ICT) continues to be one of its main areas of activity. And now, this association is no longer limited to one-on-one student consultation sessions but incorporates workshops and programs by the CWC, within 
the ICT syllabus. These workshops are designed in discussion with the instructors and keeping in mind the needs of the syllabus and the class. They address the most fundamental aspects of critical thinking required for writing and communication. Some of the workshops which were designed and conducted by the CWC for ICT classes include How to write using multiple sources; Writing around numbers; Planning a historiographical essay; What is an argument; How to write conclusions; Plagiarism and citation. These workshops are particularly designed to be a combination of lecture, discussion, and in-class exercises in reading and writing, which can be individual or done in small groups and peer review. The workshops are supplemented by one-on-one sessions. As they are part of the ICT syllabus, all undergraduates participate in these sessions which constitute the building blocks of their academic work in Ashoka.

This was the first time that these workshops were being conducted by the CWC for the ICT sections using a mixed-method approach. The feedback was tremendously encouraging. Here's an excerpt from the feedback given on a Plagiarism and Citation workshop by an ICT instructor ${ }^{7}$ :

X's approach to the overall MLA format is very calming - X shows, without overstating it, that there is a clear logic to why any kind of formatting is useful! I liked that $Y$ kept prompting the students to complete the citations that $\mathrm{X}$ would begin to explain on the white board. And I loved their hand out, with the cover and inside page of different books, with different numbers of authors, editors, translators, publishers, and then broke those down into citations. I learned stuff, too! Of course, citations can be boring to hear about, but almost every student was taking notes - even the ones hiding behind laptop screens! They must be so relieved to have someone tell them how on earth these citations work, when to use brackets, how to properly cite, and so on. ${ }^{8}$

While such a pedagogical model is useful in providing learning support to large numbers of students and at the very beginning of their academic careers, we also recognize that just one writing course over a semester is not quite enough training in reading, writing and critical thinking. This is true both for students who have fluency in English and those who lack it. At the same time, it must be recognized that all the courses in

${ }^{7}$ The two tutors who conducted the workshop are referred to as $\mathrm{X}$ and $\mathrm{Y}$.

${ }^{8}$ Aditi Sriram, email to author, September 27, 2017. 
the university may not be writing-based or may not have in-built writing mechanisms. What could be the ways in which CWC could continue to provide reading, writing, learning support to the students and faculty? There were two major initiatives taken by the CWC to address this need:

1. Creation of a year-long support system for learning the English language

2. Introduction of extra-curricular, creative programs that address reading, writing, critical thinking skills and are fun!

\section{CWC's English Language Support Program}

At Ashoka, the language of instruction is English, and even informal communication is overwhelmingly English. All instructors are fluent in English and readings/study material is exclusively in English. This poses serious problems for those students at Ashoka who may not be fluent in English.?

Within this section too, there was a great diversity in backgrounds and levels of proficiency in English language. There could be several reasons for their lack of fluency in English: they could be first-generation learners, or they may have had limited exposure to English in their school education, and that too is likely to have been poorly taught. ${ }^{10}$ In our initial interaction with the students, we were able to identify some common problems. The students often tended to reproduce their assigned readings (which were in English) verbatim and lacked individual expression, both in spoken and written exercises. They found the texts difficult to comprehend and hesitated speaking or participating in class preferring to remain silent. There was also reluctance in writing assignments-they frequently avoided writing them, eventually submitting poor quality, plagiarized content to the instructor, much after the deadline, thereby affecting their overall academic performance. Additionally, some of them were more interested and indeed more comfortable in disciplines where fluency

\footnotetext{
${ }^{9}$ At present, this number is rather small, but it continues to grow. There were five out of 935 undergraduate students in 2017-2018, and sixteen out of 1163 undergraduate students in 2018-2019, who were offered year-round, close mentoring for English language support.

${ }^{10}$ See Advani, Schooling the National Imagination, 149-169, on limitations of English language teaching in Indian schools.
} 
and expression in English mattered less, such as mathematics, physics and computer science.

We were conscious that for successful knowledge acquisition, our emphasis cannot merely be on grammatically correct English or correcting the accent. Rather, it must be on enabling the student to use the language both in everyday communication and to critically think and communicate in an academic setting. English language programs in Indian schools typically offer a text-based approach where the success of instruction is evaluated by the students' ability to correctly present the content from the reading or the book. ${ }^{11}$ As shown by Advani, '...the assumption [in English teaching is] that the text is an artefact which has to be learnt. Knowing English becomes a matter of knowing the content of the chapter, not of learning to communicate in English. ${ }^{12}$ Moreover, language teaching is commonly advanced through content, which focuses on teaching morals and building character. Advani gives examples of how the texts are full of dialogues that are unrealistic and improbable in a real life situation. ${ }^{13}$ As she points out, 'If students and teachers are shaped into believing that the English syllabus is essentially fact-based, that the important aspects are contained in memorization and rote learning, and also that the important lessons are moral ones, the acquisition of language seems secondary. ...there is little possibility of creating communicative competence here; students may pick up specific structures but they will find it difficult to apply them in other situations or learn appropriate structure.' $^{14}$

CWC's English language teaching consciously moves away from such an approach. Our emphasis is to enable the students to transition from rote learning or mechanically reproducing the texts to critical thinking. The English language support is designed in a manner that enables students to acquire and improve on skills which they can apply to other courses, and indeed, outside the university, as well. A year-long English language support program has been set up, led by two Senior Writing Tutors at the CWC: Anurima Chanda and Anderson Glashan. We begin with a short two-week bridge program before the academic semester

\footnotetext{
${ }^{11}$ Advani, Schooling the National Imagination, 152, 156.

12 Advani, Schooling the National Imagination, 156.

${ }^{13}$ Advani, Schooling the National Imagination, 153.

${ }^{14}$ Advani, Schooling the National Imagination, 164.
} 
starts. During the academic year, two credited-courses are offered by the CWC: English Communication in the Monsoon semester and Intermediate English Communication in the Spring semester. These involve classroom teaching and one-on-one sessions. Regular follow up and contact is maintained over the holiday period by the CWC tutors. In addition, the students are encouraged to schedule individual weekly sessions to support other course-related work.

Through the year, the students are frequently made to work in pairs and in small groups. Initially, our strategy for the English communication classes was to give students multiple assignments (for the purposes of assessment) which however did not prove to be very successful. We have now switched to a single assignment, allowing students to spend more time on it and to break it up into parts, working on each element separately. Further, the learning material used in class was sourced from different disciplines and themes so that the students' varied interests could be accommodated. For grammar and vocabulary, the CWC tutors were involved in designing worksheets that the students attempted and received feedback on through individual appointments every week. Both the courses incorporate exercises addressing different components of language learning which a student is expected to use in their academic life: listening, speaking, reading and writing. Some of the most popular and successful activities included the game of Taboo, working together on jigsaw puzzles and passing secrets (a game also sometimes referred to as Telephone). Taboo is a game involving word association where each player tries to explain the word on their card without using the word itself or any of the five words listed on the card. The game of jigsaw puzzles involved dividing the class into groups. One member of a team is required to arrange the jigsaw pieces by following instructions (in English) from the other team members. Passing secrets (or Telephone) is useful as a listening and speaking exercise where it became easy for students to identify changes and errors in grammar and content. Another activity required the students to write dialogues for a real-life situation (such as reporting a theft or ordering food) and enacting it in class. These exercises are designed to encourage fluency in the use of the language in everyday informal and formal communication as opposed to highly improbable dialogues typically included in English textbooks. ${ }^{15}$ Many of these activities

${ }^{15}$ Advani, Schooling the National Imagination, 153. 
have involved conscious awareness of pedagogical methods and theories along with elements of trial and error. An anecdote shared with me by my colleague, Anurima Chanda, illustrates this well. She used a translation exercise which especially resonated both with her and the students. The students were asked to translate a song from their mother tongue into English. Her observation was that the students enjoyed the activity and were even trying to sing the English version. Later, while doing research for writing a book on Dr. B. R. Ambedkar, ${ }^{16}$ for children, Chanda discovered, to her surprise and pleasure, that Ambedkar's father had used the same strategy to teach his son English! ${ }^{17}$

Equipping students to transfer their language learning to critical thinking applicable to other aspects of their academic work is an important element of English language support program offered by the CWC. This aspect of learning at Ashoka has to be addressed simultaneously as the students were already doing other reading-heavy courses in different disciplines at Ashoka. In the first instance, we tried to identify and use existing and open access learning material, such as videos on the internet which explain and illustrate concepts like 'capitalism,' 'materialism' in a simple, story-form. However, we soon realized their limitations: the students had difficulty following the accent and the examples and analogies offered as these were very specific to the cultural background of the makers of the videos (most of the videos were made in the USA).

An alternative approach used by the CWC has been more successful in this objective. It combines exercises for English language with critical learning. Again, the students are made to work in pairs. The first step in the exercise requires each student to collect biographical information about their partners. This is to encourage formulation of questions, careful listening, understanding and taking notes. In the second step, each student verbally presents a biographical note on their partners. This is an exercise in selecting information, creating a narrative and then speaking. In the third and final step, the students are required to write a paper connecting information from their partner's bio-note, to the larger world. For instance, one of the students drew upon a Tibetan student's life and

${ }^{16}$ B. R. Ambedkar (1891-1956) was a social reformer, politician and a lawyer. He was the Chairman of the committee which drafted the Constitution of independent India. He was a strong critic of the caste system and in modern India, he is particularly recognized as a champion of Dalit struggles.

${ }^{17}$ Anurima Chanda, email to author, May 21, 2019. 
particular aspects of it were used to comment upon the life in exile and government policies in India, Tibet and China. Another approach that has been successful in enabling this transition has been the extra-curricular creative programs designed by the CWC team which I discuss the following section.

The pedagogy of the English language support is designed in a way that discourages rote learning and verbatim reproduction of the content by the students. Rather, they are encouraged to discuss their ideas, express their opinions, debate and work with peers. So, this is not merely a class in correcting English grammar and pronunciation; it has significant contributions in the way students who initially lacked proficiency in English are able to engage with what appears to them as a difficult, alien and often hostile academic environment.

There are many possibilities for improvement in this teaching program. We are especially interested in exploring greater use of multilingual strategies in English language teaching. At the same time, the existing support system has made a significant difference in the work and confidence levels of the participating students. A first-year undergraduate student, who started learning English only two years before joining Ashoka, had this to say about their English Communication class:

In terms of the class timing and mode of learning, English communication was by far, the most reliable class this semester for me. I have learned a quite interesting things from the class over a period of 3 months, that I am going to remember for the next four years. ... X and $\mathrm{Y}$ have been the mentors of this class. ... The class was not just about assignments, but it also consisted of fun activities. I still remember the class where we were divided into groups and $\mathrm{X}$ made us compete against each other in three rounds. The class included of games and activities such as puzzle, finding the error in the picture and giving our opinion on one of the topics. There were classes where we were even taught the basics of reading and writing. Throughout this class, I have learned this one thing that we should never think about what others would think while we raise up and ask questions. The tips and tricks, as well as the way in which we have started analyzing our paper is the one thing that $\mathrm{Y}$ has helped us with. There was a class, where we were taught on how to maintain the continuity between paragraphs. In one of the classes we were divided into teams and given topics to debate on, that was one of the classes that made us quite comfortable while expressing our opinion. It also worked as a great 
exercise to improve our communication skills in terms of raising questions and giving sleek answers. ${ }^{18}$

Yet another student pointed out that this class helped her tackle the courses she was taking in her first year at Ashoka. A faculty member who teaches writing courses at Ashoka shared her feedback on one of the students (identified as A) who had spent a year working closely with the CWC:

I'd just like to share with you [CWC tutors] the introduction that A wrote for his final paper in my class. I assumed he had taken your help with it, because of how well it's written, but he told me he did this completely by himself. He read it out loud in front of the class and listened to feedback from his classmates on how to improve his paragraph (which you can see in the comments). It was one of the stronger introductions we reviewed in class today, along with a clear thesis statement, and I was very happy. Thanks to both of you [CWC tutors] for working with him over the past 2 semesters, and building him up to be someone who can write such a great opening paragraph! ${ }^{19}$

\section{Creative Programs}

To further promote its pedagogical vision, CWC introduced extracurricular, creative programs open to all members of the university and the public. These events innovatively draw upon and analyze a diverse range of activities and media which are part of our daily lives: news, email, music, internet, media, board games, photographs, food and jokes, to name a few. These programs are designed and executed by CWC team members and invited experts. In the last two years the CWC team organized more than twenty such events. In this section, I write about some of the most popular ones and how they engage with some of the questions raised initially in this paper.

A workshop on writing recipes was designed by Mohini Mehta, an anthropologist working on food cultures, and a Writing Tutor at the CWC. Through this two-hour workshop, Mehta was able to demonstrate recipe-writing as a literary form and skill and simultaneously a highly

\footnotetext{
18 Anonymous student feedback to course instructors.

${ }^{19}$ Aditi Sriram, email to CWC, April 17, 2018.
} 
political act. The participants included Ashoka's undergraduate students some of whom were members of the university's Baking Society, a staff member who was interested in the theme and a graduate student researching food histories. The participants worked in pairs to write recipes on a dish of their choice and in any format and literary style. The language used was English but the use of vernacular terms was encouraged. The writing exercise was followed by a discussion on the craft of writing and the politics of writing about food. One of the participants chose to write a recipe for sandwiches giving precise quantities and the exact process illustrated with a diagram. In contrast, another participant wrote a personal narrative about making $k h i c h d i,{ }^{20}$ when and why they felt the urge to make it, the memories it invoked, how they went about procuring the utensils and the ingredients, and finally how it was savored. In another narrativestyle recipe written in this workshop, the participant used a number of vernacular words to refer to particular spices and their flavors and the emotions they generate. Mehta then used these writing samples to provoke a discussion about the language of writing about food, the genderroles assumed by the participants, the stereotypes they carried, and the slangs and insults couched in one's writing especially when writing about food. She also used the discussion as an entry point into feminist and subaltern theories which consider memory and personal accounts are valid narratives. The discussion examined the celebration of food as heritage, social groups whose food was represented as cuisine, and if food could be associated with painful memories. Mehta used popular cookbooks, ${ }^{21}$ films (Marathi film, Gulabjam), and works of Dalit writers to highlight these issues.

Organizing an activity like this has many pedagogical benefits. First, and perhaps most importantly, it is fun! It interests people, makes them curious and willing to experiment and explore. Second, our creative programs are open to everyone and follow a participatory format (rather than being lecture-based). Having a teacher, a student and a staff member participate in the same activity breaks down many power relations that operate in the classroom. Barriers like English language proficiency which affect confidence and hinder participation can be reduced to a great

${ }^{20}$ Khichdi is an easy-to-cook plain dish of rice and lentils cooked together; considered a poor man's fare; often eaten while fasting, or in convalescence.

${ }^{21}$ S. Meenakshi Ammal, The Best of Samaithu Par: The Classical Guide to Tamil Cuisine (Virginia: Viking, 2001). 
extent. Third, all our creative programs follow a similar model where the resource person leading the workshop can weave a topic or activity with critical thinking, the craft of writing and communication and its politics and draw connections between multiple sources. Mehta too was successful in doing this using sources like media, film, literature and personal experience. The fourth and a very significant element of these programs is that they facilitate transfer of learning outside the classroom and outside the curriculum. While they are pitched as standalone activities, they simultaneously provide a link to the interdisciplinary academic work the students do at Ashoka. In fact, students often write back to the CWC sharing how an event they attended was useful for a course they were doing at Ashoka or their life outside the university.

Another workshop which was successful in achieving this was the one on writing feghoots-short, pun-inspired stories. The workshop was led by Karandeep Mehra, Writing Tutor at CWC, and a sociologist whose research examines humor. Mehra explains the model of these stories and the format of the workshop, 'It starts from a basic facet of language -punning. One considers the possibility that one word may have more than one meaning, or may sound like another but have different meanings, or be spelt like another word but again have different meanings. A feghootwriting workshop takes the alternate meanings and uses of a pun, finds a way to connect them by crafting them into a story such that it can end the story with the original pun. ${ }^{, 22}$ In the workshop Mehra encouraged students to identify puns, their alternative meanings, and demonstrated how this play with language can be used by advertisers, politicians and critics. A few sample feghoots were discussed and the final exercise involved students choosing a pun and weaving a feghoot around it. The success of the workshop can be gaged from the fact that days after the event some the participants continued writing to Mehra with examples of puns they identified elsewhere. Mehra plans to further explore the use of multilingual puns in CWC's work-finding similar sounds across languages, for instance, 'I laughed yesterday' in Hindi is 'Michael Hussey' (main kal hasi)!

While much of our pedagogical work in the university involves grappling with textual sources, we also explored how intangible sources like

${ }^{22}$ Karandeep Mehra, email to author, May 23, 2019. 
music could be critically analyzed and what lessons could such an exercise offer for our academic work. CWC invited Varun Kishore, a Delhibased composer and producer to create a program around active listening in music. Using a score of instrumental music, Kishore presented an analysis of the different component of this single score, introduced the participants to listening exercises identifying and isolating arrangement, rhythm and instrumentation, and concluded with a discussion of 'sampling' in music and its implications for plagiarism and citation in academic writing. Sharanya Dutta, a Writing Tutor who participated in the event remarked that the comparison of sampling with citation worked well in driving home the point about good practices in academic integrity; how existing ideas may be used by people across the world while acknowledging the source. Dutta also found the listening bias exercise effective in demonstrating that non-verbal clues can be utilized to convey context. ${ }^{23}$

In the year 2018, CWC introduced Writing Geographies, a series which explores the questions of form and politics of writing about a place and by authors located in a place. The main inspiration to initiate this series was to engage with the vast linguistic diversity of India and it is one of the initial attempts by CWC to explore the questions of language and its implications for the ideals of critical thinking and inclusive pedagogy. In the first year of its existence, we highlighted three regions within India, and the languages, writing and expression, including fiction, non-fiction, oral, visual and textual, that emerge from that region. The format of the series was flexible, some events were designed as performances, others were dialogues and discussion. Scholars, professionals, activists whose work was informed by their respective geography and language were invited to discuss their work at Ashoka.

The first in the series was a critical examination of the term 'Northeast,' officially used to identify the seven states in the eastern-most part India, and the hierarchy and power relations embedded in its usage. These questions were explored through the writings of the political scientist, Sanjib Baruah who discussed the issues of writing about the Northeast with the journalist Sangeeta Baroorah Pisharoty. Another event in the series was a conversation with a team of women reporting from the region of Bundelkhand in central India. Their initiative is called Khabar Lahariya, a

${ }^{23}$ Sharanya Dutta, email to author, May 28, 2019. 
media platform run and managed by women of Bundelkhand. They primarily use digital media, report on local issues and in local dialects of Hindi. The representatives of the Khabar Labariya team, Kavita Devi (Digital Head) and Pooja Pande (Partnerships Head) interacted with Awadhesh Tripathi (Assistant Professor of Hindi, Ambedkar University Delhi) on issues of gender, caste, class and language and the local context informing their practice of journalism. In another event, CWC invited Shalim M. Hussain, a graduate student at Jamia Millia Islamia to perform a form of protest poetry referred to as Miya poetry, being created by Muslims in the state of Assam. Miya is a derogatory slang for the Bengali-origin Muslim community in the state of Assam in northeast India. In the session, Hussain presented Miya poetry to demonstrate how an expletive has been reappropriated by the Muslim community to protest its exclusion and explored questions of the language of protest, the act of translation from local dialects to English and its relevance for the affected community.

\section{CONCLUSION}

The examples shared above convey the guiding principles and tangible implementation of CWC's work in fostering a fundamentally inclusive writing support program appropriate to an Indian liberal arts context. These programs make the teaching practices in Ashoka more democratic and actively contribute to developing a critical engagement with the world. Within the university, the CWC has carved a unique space for itself by designing learning support and offering programs within the curriculum, while simultaneously going beyond the syllabus. As a result, the CWC has emerged as a platform where all members of Ashoka and even the wider academic community in India participate, debate, and critically engage with texts, languages, materialities, pedagogy and inclusion.

Going forward, the CWC and indeed, similar writing centers that have recently been established in other universities in India, have tremendous scope for contributing to the landscape of higher education in India and Asia. The CWC intends to develop its work to create an open access knowledge bank that shares the teaching material created by its tutors and instructors. This resource can be further developed by educators to cater to their specific contexts, and even for teacher training. The next step would be making it available in at least a few major Indian languages, besides English. There are many studies that highlight the benefits of 
multilingual education at school level in the Indian context, and its relationship to development and inclusion. ${ }^{24}$ It would be useful to explore its benefits in higher education. The writing center as an institution (in Ashoka and elsewhere) has the potential to emerge as a pioneering space to research and experiment with multilinguism, interdisciplinarity, pedagogy and inclusion in higher education.

Acknowledgement I am grateful to Shivani Nag of Ambedkar University Delhi for discussing this theme with me and offering valuable suggestions for this paper. I would like to thank all my colleagues at the CWC who have contributed to the team's work. I would especially like to acknowledge the colleagues whose work I have discussed here: Anurima Chanda, Anderson Glashan, Mohini Mehta, Karandeep Mehra, Sharanya Dutta, Jyotirmoy Talukar, Mayuri Patankar, Varun Kishore and Aditi Sriram.

\section{BIBLIOGRAPHY}

Advani, Shalini. Schooling the National Imagination: Education, English, and the Indian Modern. New Delhi: Oxford University Press, 2009.

Coleman, Hywel, ed. Multilingualism's and Development: Selected Proceedings on the 11th Language and Development Conference, New Delhi, India, 2015. New Delhi: British Council, 2017.

Freire, Paulo. Pedagogy of the Oppressed. Translated by Myra Bergman Ramos. Great Britain: Penguin, 1972.

hooks, bell. Teaching to Transgress: Education as the Practise of Freedom. New York and London: Routledge, 1994.

Ramanathan, Vaidehi. The English-Vernacular Divide: Postcolonial Language Politics and Practice. New Delhi: Orient Longman, 2005.

Skutnabb-Kangar, Tove, Robert Phillipson, Ajik K. Mohanty, and Minati Panda, eds. Social Justice Through Multilingual Education. Bristol: Multilingual Matters, 2009.

Wolf, Maryanne. Reader, Come Home: The Reading Brain in a Digital World. New York: HarperCollins, 2018.

${ }^{24}$ Tove Skutnabb-Kangar, Robert Phillipson, Ajik K. Mohanty, and Minati Panda, eds., Social Justice Through Multilingual Education (Bristol: Multilingual Matters, 2009); Hywel Coleman, ed., Multilingualism's and Development: Selected Proceedings on the 11th Language and Development Conference, New Delhi, India, 2015 (New Delhi: British Council, 2017). 
Open Access This chapter is licensed under the terms of the Creative Commons Attribution 4.0 International License (http://creativecommons.org/licenses/ by $/ 4.0 /$ ), which permits use, sharing, adaptation, distribution and reproduction in any medium or format, as long as you give appropriate credit to the original author(s) and the source, provide a link to the Creative Commons license and indicate if changes were made.

The images or other third party material in this chapter are included in the chapter's Creative Commons license, unless indicated otherwise in a credit line to the material. If material is not included in the chapter's Creative Commons license and your intended use is not permitted by statutory regulation or exceeds the permitted use, you will need to obtain permission directly from the copyright holder.

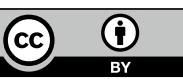

